\title{
Para além da homogeneidade cultural: a cultura organizacional na perspectiva subnacional
}

\author{
Beyond cultural homogeneity: organizational culture in a subnational perspective
}

\author{
Henrique Muzzio ${ }^{1}$ \\ Francisco José da Costa ${ }^{2}$
}

\begin{abstract}
Resumo
Este artigo tem como objetivo discutir os estudos culturais organizacionais e propor um modelo teórico de análise a partir de uma nova dinâmica espacial que leva em consideração as interações sociais marcadas pela relação entre o global e o local. Sua importância decorre da proposição de um modelo que analisa a cultura organizacional sobre um prisma subnacional, superando a visão homogênea de cultura nacional. O pressuposto é que diante da existência de novas condições sociais da pós-modernidade, as organizações precisam ser interpretadas também à luz dos valores culturais regionais. Assim, a partir do modelo apresentado, propomos uma explicação de como as forças globais e regionais interagem através de fluxos culturais, e como influenciam o contexto cultural organizacional. São discutidas ainda implicações práticas desta abordagem em algumas áreas organizacionais que são naturalmente mais influenciados pelo contexto cultural. Uma evidência prática é discutida a partir do contexto cultural brasileiro. Ao final, são feitas proposições para futuras pesquisas com o intuito de consolidar o modelo teórico, e dar robustez ao campo.
\end{abstract}

Palavras-chave: Cultura subnacional. Cultura organizacional. Espaço regional. Fluxos culturais.

\begin{abstract}
The main objective of this article is to debate organizational culture studies considering a new spatial dynamic, and considering the social interactions that are marked by the relationship between the global and the local, with the presentation of a proposed analytical framework. Its importance stems from the proposition of the framework, which presents and analyses organizational culture from a subnational perspective, going beyond the homogeneous view of the national culture. It is supposed that, considering the new postmodern social conditions, organizations need to be interpreted according to regional cultural characteristics. Through this framework, we offer an explanation as to how global and regional forces interact alongside the cultural flows, and how this influences the organizational cultural context. We discuss some practical implications of the approach for some of the main managerial fields that are more evidently influenced by the regional characteristics, and the Brazilian case is taken as empirical evidence. In the end, some ideas are presented for future research, specifically with a view to improving the framework and also to contributing to a more robust development of the organizational cultural field.
\end{abstract}

Keywords: Subnational culture. Organizational culture. Regional space. Cultural flows.

Artigo submetido em 09 de novembro de 2010 e aceito para publicação em 19 de julho de 2011.

1 Doutor em Administração pela Fundação Getulio Vargas/EAESP; Professor da Universidade da Integração Internacional da Lusofonia Afro-Brasileira (UNILAB). Endereço: Rua Rangel Pestana 950, complemento 18, Sapiranga, CEP 60833-012, Fortaleza-CE, Brasil. E-mail: hmuzzio@gvmail.br

2 Doutor em Administração pela Fundação Getulio Vargas/EAESP; Professor do Programa de Pós-Graduação em Administração da Universidade Federal da Paraíba (PPGA/UFPB) e da Universidade da Integração Internacional da Lusofonia Afro-Brasileira (UNILAB). Endereço: Rua Jorge Dumar, 2001, Montese, CEP 60410-426, Fortaleza-CE, Brasil. E-mail: franze@franzecosta.com 


\section{Introdução}

Este artigo tem como objetivo discutir os estudos culturais organizacionais, e propor um modelo teórico de análise, levando em consideração, a partir de uma nova dinâmica espacial, as interações sociais marcadas pela relação entre o global, o nacional, o regional e o local. Ao longo das últimas três décadas, muitos estudos foram conduzidos tratando a cultura e a nação como se fossem sinônimas (e.g. HOFSTEDE, 1980; NELSON e GOPALAN, 2003). Os achados dessas investigações admitem em geral uma homogeneidade no lócus de pesquisa, porém, se isso pode ser adequado para algumas nações, em outras tais estudos podem ser incompletos, quando observadas as realidades subnacionais culturalmente heterogêneas. A importância deste trabalho repousa, portanto, em estender o debate dos estudos interculturais para um contexto dentro dos países, superando assim uma visão de uniformidade cultural nacional que prevalece neste campo.

O contexto organizacional pode ser interpretado por diferentes perspectivas, se replicarmos as lentes usadas nas ciências sociais: a ciência positivista (DONALDSON, 2003), a ciência interpretativa (HATCH e YANOW, 2003), a ciência crítica (WILLMOTT, 2003) e a ciência pós-moderna (CHIA, 2003). O positivismo entende o mundo como algo real e objetivo, no qual podemos analisar a realidade de forma independente. $\mathrm{O}$ interpretativismo baseia-se na indeterminação de causalidades, na impossibilidade de generalizações, na contextualização dos achados e na dependência do observador. Os críticos trabalham com uma perspectiva da emancipação humana, e censuram as condições prevalecentes no contexto organizacional. No pós-modernismo, a interpretação ocorre segundo os valores e a cultura do pesquisador. Segundo Boisot e Mckelvey (2010), esse último paradigma introduz a linguagem entre o observador e o mundo externo, em que há um contexto social possuidor de interesses externos e relações de poder, e em que o contexto cultural e o histórico rivalizam com a ideia de verdade objetiva.

Representantes de cada paradigma rivalizam-se para explicar o mundo social e organizacional. A literatura funcionalista, por exemplo, é baseada nos preceitos do positivismo, e seus autores expõem a tentativa de apresentar explicações universais aos fenômenos sociais, reduzindo a complexidade ambiental através de modelos que procuram elucidar as mudanças sociais (FLICK, 2004). Diante de um cenário de incertezas que caracteriza uma boa porção do universo organizacional e da incapacidade dessa abordagem, com sua visão instrumental de explicar o que ocorre nesse universo, as pesquisas interpretativistas ganham corpo na academia como lente de investigação social (DENZIN e LINCOLN, 2005)

Tais pesquisas possuem um foco de análise que se preocupa em explicar fenômenos específicos, como apresentado acima, e não têm a preocupação de generalização, dado que a realidade é vista como algo inerente a um contexto específico. Em outras palavras, as explicações para as culturas organizacionais são associadas a um espaço que possui dinâmica própria e a uma realidade temporal específica.

Entende-se assim que o espaço e o tempo são condicionantes privilegiados da existência e das relações humanas. No passado, a ideia de espaço como algo estático e do tempo como algo dinâmico foi suficiente para explicar as condições sociais nos âmbitos geográfico, político, histórico e sociológico. No entanto, teorias contemporâneas relatam novas concepções do espaço desprendido do tempo, sendo esta uma das mais marcantes características dessa época, mesmo com diferentes denominações, tais como, a modernidade tardia (GIDDENS, 1990), a modernidade líquida (BAUMAN, 2000), a pós-modernidade (HARVEY, 1992) ou a hipermodernidade (LIPOVETSKY, 2004).

Especificamente sobre o espaço, esse já não pode ser interpretado como um simples conceito métrico, mas sim como um lócus de relações sociais (LEFEBVRE, 1991) que estão imbricadas com todo o contexto global através de influências mútuas. Tais relações ocorrem sobre intensa fluidez de ideias, de conceitos, de padrões comportamentais, dentre outros aspectos que se redesenham através da relação global-local.

Associado à questão espacial, podemos considerar a cultura como uma importante variável que condiciona o comportamento coletivo. Através de modelos que são reputados válidos e suficientes pela sociedade para garantir relações sociais relativamente estáveis (PETTIGREW, 1979; TRICE e BEYER, 1984; VAN DEN 
BERG e WILDEROM, 2004), o espaço pode ser concebido como um delimitador da legitimidade social que caracteriza a cultura.

Especificamente para o contexto organizacional, o espaço torna-se um privilegiado lócus de compreensão da cultura das organizações quando essas passam a atuar em diferentes contextos espaciais, tanto em nível internacional, como em nível regional. Condições espaço-temporais específicas podem significar novas formas de interpretação e de entendimento organizacionais.

Nesse sentido, este artigo defende a pertinência de se reconhecer as diferenças subnacionais em nações com realidades culturais regionalizadas para que melhor se compreenda o contexto organizacional nesses ambientes heterogêneos. Para tal, apresentamos mais seis seções além das considerações finais, a saber: a primeira promove o debate entre as noções de heterogeneidade e de homogeneidade cultural; a segunda discute as novas concepções que definem a lógica espacial contemporânea; a terceira foca na temática da relação da cultura organizacional com o espaço; a quarta descreve o modelo teórico que conjuga a relação global e local na cultura organizacional; e a sexta traz um exemplo da realidade cultural brasileira e sua condição de heterogeneidade regional.

\section{Cultura e a Questão da Homogeneidade/Heterogeneidade}

A cultura é uma condição humana que molda e é moldada pelo homem. A despeito de variadas correntes teóricas do que seja cultura, apoiamo-nos em Geertz (1989) que a interpreta como algo que é compartilhado pelos homens, fazendo uso de elementos simbólicos. Segundo esse autor, "acreditando, como Max Weber, que o homem é um animal amarrado a teias de significados que ele mesmo teceu, assumo a cultura como sendo essas teias e a sua análise; portanto, não como uma ciência experimental em busca de leis, mas como uma ciência interpretativa, à procura do significado" (GEERTZ, 1989, p. 15).

Dentre as bases da identidade cultural, exemplificamos os antecedentes histórico-geográficos (memória comum, colonização), os econômicos (ciclos econômicos, modelo de exploração econômica), os institucionais (legislação) e os simbólicos (mitos comuns). Peterson e Smith (1997), por exemplo, defendem o território histórico ou a pátria, os mitos, a memória histórica, a cultura de massa pública, os direitos legais, e a economia com mobilidade territorial para seus membros como as bases da identidade nacional.

Diante dessas bases da identidade cultural e de sua forte influência nos estudos organizacionais (BLYTON, 2001), um debate instigante nas últimas duas décadas foi o que discutiu se a cultura mundial estava caminhando para uma convergência ou ampliando sua diversidade, sendo o vetor dessa questão a intensificação da mundialização/globalização nas últimas décadas e seus reflexos nos contextos locais.

Se no início alguns viam como ponto negativo a uniformidade cultural, o tempo foi capaz de dissipar esse temor, quando se percebeu que a globalização não levou a uma homogeneidade cultural como se imaginava (GUIBERNAU, 1997; HALL, 2001) ou mesmo como se temia (CANCLINI, 2005), ao contrário, ressaltou a diversidade de culturas. Conforme afirma Giddens (1996, p. 96-97): "não existe um movimento unilateral em direção à homogeneidade cultural. A globalização também leva a uma insistência da diversidade, uma busca de recuperação de tradições perdidas e uma ênfase na identidade cultural local". Spicer (2006) vai além da discussão convergência-divergência e afirma existir uma transformação em diferentes localidades espaciais, fruto da translação entre os contextos global e local, bem como da hibridização presente nesse processo.

Gould e Grein (2009) definem a cultura global como vários cenários ou largas esferas culturais que incorporam os fluxos globais das ideias, das pessoas (cultura global do consumidor), das imagens, do capital, da tecnologia e dos tipos em uma relação dialética global-local, o que os autores denominam de glocalização. Este conceito apropria a ideia de ocorrer uma sobreposição das forças globais no contexto local e uma consequente uniformidade cultural, mas também de um movimento ambíguo. Ou seja, a globalização 
fragmentou fronteiras (PAASI, 2002), e levou a uma valorização das questões locais e ao fortalecimento da busca de autonomia local, bem como da identidade cultural regional (GIDDENS, 1990; GUIBERNAU, 1997; KUMAR, 1997; HALL, 2001; LIPOVETSKY, 2004; CANCLINI, 2005; PESQUEUX, 2007; PRASAD, A. e PRASAD, P., 2007). A mútua influência entre o global e o local é possível porque as pessoas podem se apropriar, resistir, ou hibridizar os vários fenômenos globais (GOULD e GREIN, 2009).

As forças globais e locais propagam-se através dos fluxos culturais (LLOYD, 2002; PRASAD, A. e PRASAD, P., 2007) que são "sequências intencionais, repetitivas e programáveis de intercâmbio e interação entre posições fisicamente desarticuladas, mantidas por atores sociais nas estruturas econômica, política e simbólica da sociedade" (CASTELLS, 1999, p. 436). Suas categorias centrais são: os fluxos de pessoas, de capital, de informação, de interações sociais e organizacionais, de imagens e símbolos. Tais fluxos alcançaram grande capacidade de deslocamento, porém, não o fazem de forma homogênea. Ou seja, a intensidade, o alcance e as consequências dos fluxos se dão de forma diferenciada geográfica e culturalmente. Dada a condição de aniquilação do espaço pelo tempo, a desterritorialidade, a virtualidade e as novas ferramentas de comunicação e de deslocamento (GIDDENS, 1990; HARVEY, 1992; BAUMAN, 2000; LIPOVETSKY, 2004), a cultura encontra livre trânsito no globo terrestre para circular, utilizando-se de um contexto maior de condições sociais, políticas e operacionais, facilitando a mobilidade de ideias, de costumes, de valores, de práticas etc. e gerando uma das maiores características do século XXI, a interdependência do mundo, causada pelas muitas relações transacionais, pelos processos e pelos fluxos culturais (CASTELLS, 1999).

Canclini (2005, p. 41) afirma que a cultura abarca o "conjunto de processos sociais de produção, circulação e consumo da significação na vida social", e que esses processos não acontecem da mesma maneira nas regiões. Nesse sentido, os fluxos culturais também contribuem para que as culturas nacionais ganhem uma dimensão fluida, e acentue suas diferenciações internas. A cultura é vista, então, como resultante da integração entre os fluxos culturais mundiais e regionais, que ganham contornos específicos a partir de ressignificações apoiadas em valores locais, o que garante uma heterogeneidade cultural, ainda que haja forças institucionais convergentes (SCOTT, 2001).

Essa perspectiva entende que culturas podem ser diferenciadas regionalmente nos países, ou seja, no nível subnacional. MacNab, Worthley e Jenner (2009) utilizam o termo microcultura e o conceituam como um mosaico dinâmico (às vezes líquido) existente em uma sociedade complexa, tal como uma nação diversa e extensa, que externa uma variedade dos agrupamentos menores, originais e importantes, que compõem juntos um quadro total. Segundo McSweeney (2009), a sociedade e as organizações são tão diversas, as influências são tão múltiplas, as fronteiras são tão porosas, os problemas são tão numerosos, que a compreensão da noção de cultura nacional necessita de modelos interacionais complexos.

Autores como Hall (2001), Santos e Silveira (2006) e Prasad, A. e Prasad, P. (2007) analisam as distinções regionais em países as quais são oriundas dos efeitos heterogêneos da globalização no nível subnacional. Fatores como a complexidade das cadeias produtivas, o volume das trocas comerciais internacionais, a qualidade e diversidade da infraestrutura de transporte e de comunicação, o volume das transações econômicas internacionais, dentre outros aspectos, serviriam para criar essas diferenciações. Canclini (2007) ainda usa como critérios a forte presença de empresas transacionais, a mistura multicultural de habitantes nacionais e estrangeiros, o prestígio decorrente da concentração de elites artísticas e científicas e a alta porcentagem de turismo internacional.

Essa nova condição de interposição de forças globais e locais e a consequente diferenciação regional faz emergir uma nova possibilidade de análise do espaço enquanto lócus de convivência cultural.

\section{A Questão Espacial e da Heterogeneidade}

Historicamente, a questão espacial tem sido objeto de preocupação no campo social. Em uma proposta consistente de organização do conceito, Lefebvre (1991) trabalhou conjuntamente os conceitos de: i) espaço 
físico (natureza) em que emergem as práticas espaciais que se referem à dinâmica da produção; ii) espaço mental (abstrações lógicas e locais), em que se dão as representações de espaço que envolvem o conhecimento, os signos, os códigos, que permitem a compreensão das práticas espaciais através de uma linguagem; iii) $\mathrm{O}$ espaço social (representacional) que envolve a significação das experiências sociais. Para este artigo esta é a visão considerada para a expressão espaço.

Tradicionalmente, o tempo foi um critério usado para separar acontecimentos, e o espaço foi um critério útil para separar corpos e objetos. Na sociedade contemporânea, com a expansão da comunicação, das redes de transmissão de dados, o surgimento da virtualidade, por exemplo, o tempo adquire valor. Atualmente, tempo e espaço já não estão imbricados. Acontecimentos em diferentes contextos geográficos não são impeditivos para a conexão das ações sociais em virtude da compressão do tempo-espaço (GIDDENS, 1990) ou, como prefere Harvey (1992), do aniquilamento do espaço pelo tempo. Tais concepções contemporâneas, que desvinculam tempo e espaço, são objetos de variadas facetas de observação que se encontram justamente na possibilidade de acontecimentos simultâneos e vinculados em diferentes contextos espaciais.

Novas concepções de espaço surgem diante de um mundo pós-moderno (HARVEY, 1992) que exige reposicionamentos sociais em diferentes perspectivas, como no comportamento, na interação, na interculturalidade, na política, na economia, dentre outros. Mitchell (2002), por exemplo, defende que atualmente as fronteiras são porosas, variando não apenas por nação ou pelo regime político, mas por tipos de fluxos e por narrativas particulares da nação ocorridas em momentos diferentes. Se antes o Estado era concebido como uma entidade completa e circunscrita, no período contemporâneo da globalização, o papel e as fronteiras do Estado estão em fluxo constante (MITCHELL, 2002).

Castells (1999) fala em espaço de lugares e espaço de fluxos, sendo seguido por Väyrynen (2003) quando este distingue entre as regiões físicas e as funcionais. As primeiras referem-se aos espaços territoriais, militares e econômicos, controlados primeiramente por Estados; as outras, por outro lado, referem-se às regiões funcionais que são definidas pelos fatores não territoriais, tais como a cultura e o mercado, e que são frequentemente protagonizados por atores não estatais.

Durante a década de 1990, as fronteiras e limites tornaram-se palavras-chave em ciências sociais, e os estudos culturais mudaram em razão deste fato. Pesquisadores têm desafiado as ideias de limites fixos, de identidades, de verdades, e de poder, ressaltando a natureza fragmentada das fronteiras. Os limites são, na verdade, processos culturais dinâmicos, e são mais do que linhas sobre um mapa. Eles têm links cruciais com a identidade, com a ação, com a mobilidade, e com a energia de que necessitamos para compreendermos as mudanças espaciais do mundo globalizado (PAASI, 2002).

Isso ocorre em função das fronteiras serem atribuições simbólicas, ou seja, são constituídas por processos culturais baseadas em discursos, e são consequência de uma construção social da realidade (BERGER e LUCKMANN, 2004). E, como tal, não necessariamente ficam vinculadas a delimitações políticas. Nesta ótica, as culturas nacionais ganham outro significado. Hall (2001) afirma que

Em vez de pensar as culturas nacionais como unificadas, deveríamos pensá-las como constituindo um dispositivo discursivo que representa a diferença como unidade ou identidade. Elas são atravessadas por profundas divisões e diferenças internas, sendo 'unificadas' apenas através do exercício de diferentes formas de poder cultural. Entretanto como nas fantasias do eu 'inteiro' de que fala a psicanálise lacaniana - as identidades nacionais continuam a ser representadas como unificadas (HALL, 2001, p. 62).

Um exemplo da ampliação da perspectiva cultural é oferecido por Gould e Grein (2009). Estes autores defendem que uma cultura nacional não é um conceito único, pois essa cultura é formada por comunidades que superaram a concepção clássica. Eles dividem essas comunidades em quatro tipos: a geografia cultural; as organizações e as instituições; as comunidades baseadas em um estilo de vida; e as comunidades baseadas 
em características pessoais nas quais cada uma possui características próprias e interações sociais específicas, fazendo com que haja diversidade cultural em nível subnacional.

Enfim, essa literatura mostra o quanto a cultura nacional pode se distender de sua concepção tradicional. Novas perspectivas acabam por superar uma delimitação política, e tanto podem estender os compartilhamentos de valores a outras nações, como podem congregar diferentes culturas em uma única nação. Tal condição abre também novas perspectivas para o contexto organizacional, que passa a superar uma pretensa homogeneidade nacional, enquanto um referencial de espaço.

\section{A Cultura Organizacional e o Espaço}

Dentre as muitas perspectivas possíveis para a compreensão das organizações e seu comportamento, a cultura organizacional tornou-se, nas últimas três décadas, uma lente privilegiada diante da capacidade dessa perspectiva de analisar como as práticas e os comportamentos organizacionais são afetados por padrões sociais. Os estudos culturais se caracterizaram pela profusão de perspectivas de análises (SOIN e SCHEYTT, 2006) que advêm de concepções contraditórias relacionadas à ontologia, à epistemologia, aos métodos de investigação utilizados e às estratégias de escrita (SMIRCICH, 1983; MARTIN e FROST, 1996; MARTIN, 2003).

Em oposição à visão funcionalista de cultura (SCHEIN, 2004; TOMITÃ, STUPARU, TANCIU et al., 2010), a perspectiva interpretativista busca a compreensão organizacional por meio dos seus aspectos simbólicos (TURNER, 1986), que se manifestam através de rituais (TRICE e BEYER, 1984) de significados próprios a um contexto específico. Nesta linha, definimos cultura organizacional como uma rede de significações que circulam dentro e fora do espaço organizacional, que é usada como instrumento de poder, que são criadas e recriadas nas relações cotidianas, sendo simultaneamente ambíguas e contraditórias, revelando a coesão e a fragmentação organizacionais (MARTIN, 1992; FREITAS, 2007).

Sob a perspectiva espacial, a abordagem funcionalista analisa a cultura organizacional, prioritariamente, com estreita relação com a cultura de um país, normalmente fazendo o uso de técnicas quantitativas que trabalham com a perspectiva das nações possuírem um padrão bem delimitado de classificação e uma concepção ética de cultura (MARTIN, 2003). Muito desse padrão de pesquisa deve-se ao trabalho proeminente de Hofstede (1980). Ele ganhou o reconhecimento internacional (TSUI, NIFADKAR e OU, 2007), ao aplicar em diversos países um modelo de categorias (individualismo x coletivismo; aversão à incerteza; masculinidade x feminilidade; orientação para o longo prazo x curto prazo) que classifica processos sociais por culturas nacionais, em função de como essas culturas nacionais percebem e interpretam o mundo, tornando-se uma referência no campo.

Por outro lado, se entendermos que a cultura está relacionada com padrões coletivos considerados coerentes, torna-se difícil defender que os valores compartilhados possam ocorrer em algumas nações, apenas limitados por definições legais, como as fronteiras oficiais, aspecto esse socialmente construído e que muitas vezes não reflete a diversidade cultural de seus membros. Nesses espaços pode prevalecer uma diversidade cultural originada em questões seculares de raça, de religião, de etnias, de dinâmicas socioeconômicas, por exemplo, sendo comum a existência de hibridismos, de fragmentações, de ambiguidades, de contradições (MCSWEENEY, 2009) que precisam ser levadas em consideração quando da compreensão de certos elementos da cultura organizacional, notadamente, aqueles que envolvem interações sociais externas.

Embora, para determinadas nações, uma abordagem homogênea de cultura nacional não seja algo inapropriado, para outras, a vinculação com uma cultura única pode ser uma visão reducionista, e não propiciar um entendimento mais próximo e específico de sua multiplicidade cultural presente em seus diversos espaços. 
Essas duas visões ofereceram um debate, nos últimos anos, entre os estudos culturais mais tradicionais, que normalmente usam o país como um sinônimo de espaço cultural homogêneo (HOFSTEDE, 1980; KOSTOVA e ROTH, 2002; LAROCHE, PAPADOPOULOS, HESLOP et al., 2003; ELENKOV e KIROVA, 2008) e aqueles que reconhecem as nações como uma integração de espaços culturalmente heterogêneos (MEEK, 1988; LENARTOWICZ e ROTH, 2001; SARWONO e ARMSTRONG, 2001; NELSON e GOPALAN, 2003; COHEN, 2007; TSUI, NIFADKAR e OU, 2007; SINGH, SRINIVASAN, SISTA et al., 2008; MCSWEENEY, 2009; MACNAB, WORTHLEY e JENNER, 2009; MUZZIO, 2010a).

Para estes últimos autores, no contexto organizacional, há também a possibilidade de diferenciações subnacionais decorrentes dos fluxos culturais, que acabam por favorecer a intensificação do hibridismo cultural, fato relacionado à interação de culturas através da justaposição de elementos globais e locais. Em outras palavras, o hibridismo está associado à heterogeneidade (diversidade de constituição), à multiplicidade (mistura de elementos) e a uma autenticidade própria, não sendo apenas uma simples e nova interpretação de uma tradição (CANCLINI, 2005) e que, no contexto organizacional atual, pode ser interpretado como uma junção de elementos arcaicos, modernos e pós-modernos em uma convivência híbrida de significados que evidenciam culturas múltiplas e fragmentadas (CALÁS e ARIAS, 1997).

Neste sentido, abre-se outra dimensão de análise cultural: o subnacional. Este novo nível de interesse acaba por se refletir na análise organizacional, que já é interpretada, por exemplo, através de sua natureza fragmentada e ambígua (MARTIN, 1992; MARTIN e FROST, 1996; MORGAN e OGBONNA, 2008) e agora pode também ser analisada pela interpretação e simbologia regional.

Spicer (2006) defende que a produção social ocorre através do que chamou de escalas espaciais, ou seja, níveis de interação social. Além de sua aplicabilidade genérica, o autor considera essa perspectiva útil para ser usada no contexto organizacional. Essas escalas ocorrem através de três processos inter-relacionados: i) a acumulação capitalista, que força os fluxos de investimentos e as infraestruturas a se configurarem similarmente no nível global, dando como exemplo, o setor bancário; ii) a regulação, mecanismo regulatório normalmente encontrado no nível nacional; iii) a articulação de discurso político, que é carregado de subjetividade e que permite a construção de fronteiras simbólicas de escalas espaciais. Com isso, ele distingue níveis espaciais que interagem e influenciam as relações organizacionais.

Neste sentido, organizações que atuam em países com diversidade cultural regional, através de diferentes unidades funcionais, passam a ter uma nova vertente para compreender como os valores regionais interferem nos valores de seus membros, e como isso interfere na interpretação das práticas organizacionais e de sua própria cultura. Ainda que existam elementos culturais e normas organizacionais uniformes que se sobrepõem a todas as unidades, os valores regionais possibilitam leituras diferenciadas da realidade entre as unidades. Além disso, os processos sociais e organizacionais podem ocorrer simultaneamente nos níveis global e regional.

\section{O Modelo Teórico Proposto}

O modelo teórico proposto para visualização e incorporação da dimensão espacial na análise organizacional está representado pela Ilustração 01. Nela é possível, inicialmente, acompanharmos a interação dos contextos global e regional. O primeiro contexto, o global, é marcado em função: i) dos efeitos da globalização/mundialização, que ocorrem na economia, na política, na cultura, por exemplo (CASTELLS, 1999); ii) da homogeneização cultural, que significa a possibilidade de que os fluxos culturais globais tornem homogêneas determinadas condições sociais, tais como os processos industriais, os meios de comunicação etc. (GIDDENS, 1990); iii) da compressão do espaço e do tempo (HARVEY, 1992).

O contexto global interage com um segundo contexto considerado no modelo, que é o regional, e que é caracterizado por: i) ressignificações locais, que decorrem de reações de movimento sociais locais que não 
concebem uma massificação completa de sua cultura e de seus valores (MITCHELL, 2002); ii) fronteiras permeáveis, que se deslocam em função dos fluxos culturais, de identidades locais e da flexibilidade na interpretação das delimitações oficiais (GOULD e GREIN, 2009); iii) heterogeneidade cultural, que ocorre em função da diversidade de constituição dos valores sociais subnacionais (LENARTOWICZ e ROTH, 2001; CANCLINI, 2005), diversidade esta cada vez mais reconhecida em um contexto pós-moderno.

\section{Ilustração 1}

\section{Esquema teórico}

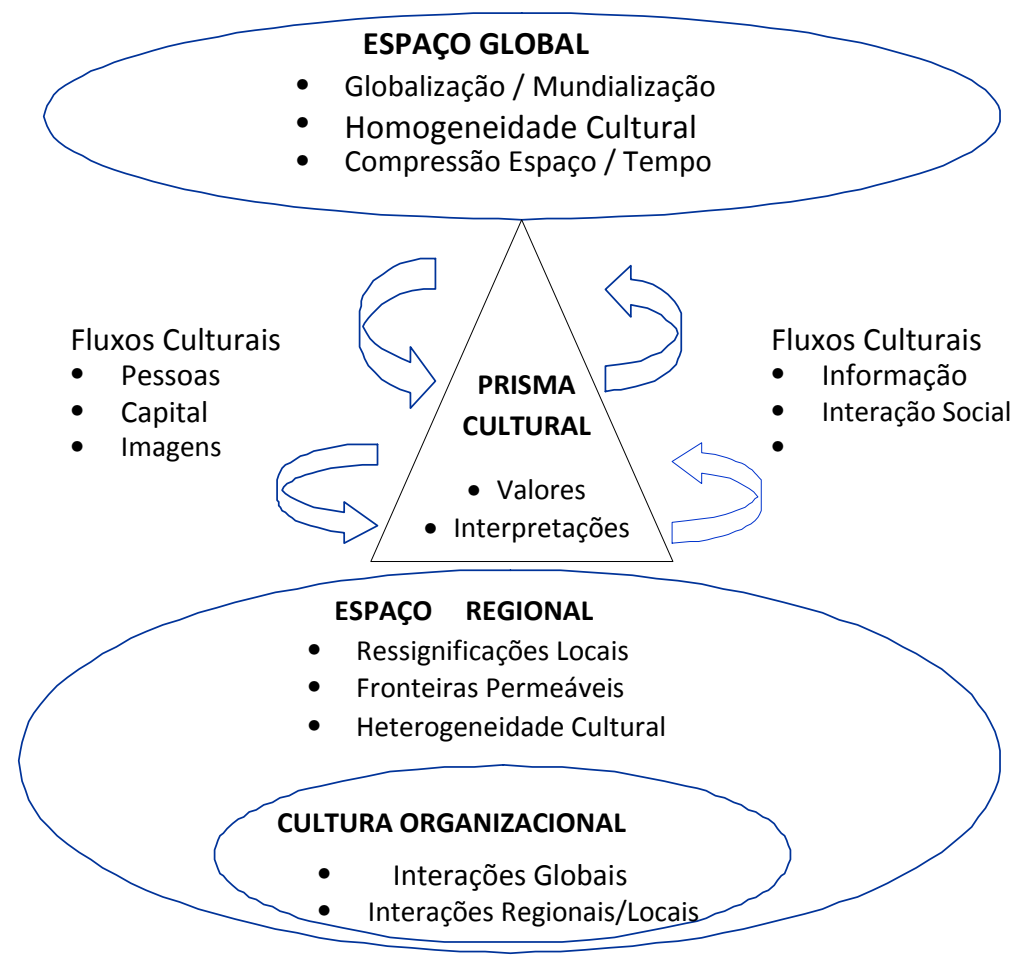

Fonte: Elaborado pelos autores.

Facilitado pelo desenvolvimento dos meios de deslocamento e de comunicação, estes dois contextos se interligam através dos fluxos culturais (CASTELLS, 1999; LLOYD, 2002; PRASAD, A. e PRASAD, P., 2007) tais como os símbolos, a informação, as imagens, o capital, as pessoas, dentre outros, e se direcionam tanto no sentido global-local, como no sentido local-global. Tais fluxos são refratados através de um prisma cultural ao cruzar as fronteiras simbólicas de ambos os lados. Fazendo uma associação ao conceito de espaço funcional (VÄYRYNEN, 2003), o prisma cultural levaria a interpretações e a valorizações diferenciadas entre as comunidades locais, como por exemplo, na aceitação de ideias, de produtos e de tecnologias. Como ilustração, o fluxo de pessoas tem modificado a realidade demográfica em muitas regiões, como é o caso dos Hispânicos nos Estados Unidos e dos Mulçumanos no Continente Europeu, realidade que cria novas demandas sociais e organizacionais.

O modelo admite que é no contexto regional que vai se constituir um contexto da cultura organizacional, no qual as interações das organizações ocorrem, tanto em nível global quanto em regional/local. Assim, forças globais são responsáveis por respostas isomórficas que unificam, por exemplo, alguns procedimentos administrativos e ferramentas de gestão (SCOTT, 2001). Por outro lado, as interações regionais favorecem, por exemplo, as adaptações mercadológicas e as relações pessoais (MCSWEENEY, 2009). 
Nesta perspectiva, entende-se que a característica formadora da unidade organizacional encontra-se primeira e principalmente delineada a partir de uma esfera de determinação regional, de modo que os condicionamentos globais alcançariam, na forma de influência, a cultura das organizações por meio da interação e dos fluxos culturais com o nível regional. Uma consequência imediata desta visão de constituição da cultura organizacional é a necessidade de uma reconfiguração de modelos interpretativos, na medida em que as variáveis de natureza regional precisam ser consideradas como princípios da análise organizacional.

Esse modelo proposto pode ser explorado sob uma perspectiva epistemológica intersubjetiva, na qual novas configurações adicionam possibilidades híbridas que não são nem totalmente objetivas e nem subjetivas (CULIFFE, 2010). Isto permite analisar o modelo também por uma lógica da prática gerencial aliada a elementos subjetivos e culturais. Nesse sentido, em nível de consequências desta visão, é possível compreender que a ação gerencial pode sofrer condicionamentos desta mesma natureza. Ou seja, algumas manifestações da prática administrativa terão sua possibilidade de eficiência e sua formatação condicionadas pelas características presentes no contexto regional. Considerando que essa perspectiva não impede que a prática gerencial receba influências do contexto global, como ocorre, por exemplo, no contexto da administração de operações, que costuma ter um alinhamento com as tendências e inovações divulgadas em nível global, nossa proposta realça que uma porção significativa dos condicionamentos da dinâmica gerencial de cada área funcional vem de uma esfera de determinação regional (a própria área de administração da produção não prescinde da necessidade de adaptação de modelos globais às características regionais que viabilizem, por exemplo, sua aceitação pela classe operária em serviço ou sua capacidade de apropriação na prática de produção).

\section{Uma Discussão Específica: o Caso Brasileiro}

A possibilidade de que as significações locais possam variar regionalmente potencializa o viés espacial da cultura de um país, no sentido de compreender como e em que intensidade os elementos globais estão presentes em determinado contexto regional. A associação entre cultura e região é histórica, pois as áreas culturais são territórios geográficos onde existem culturas semelhantes, e em que os traços ou as características culturais resultam em um modo específico de ser dos grupos. Esse conceito ganha maior dimensão com a ampliação de seu escopo, de uma divisão administrativa para dimensões simbólicas mais ricas que passam a diferenciar áreas culturais.

Uma significação é decorrente das relações internas do sistema a que este pertence. Qualquer organização opera em um determinado contexto, e os significados que a permeiam são, portanto, referenciados pelos valores do ambiente, que podem possuir diferentes níveis de análise. Neste sentido, a cultura organizacional pode se referenciar simultaneamente em um ambiente mundial, nacional e regional/local, quando tal nível justificar uma análise distinta do nível nacional. No caso brasileiro, a literatura indica diferenças culturais que podem legitimar análises no nível regional, o que nos leva a compreender esta regionalidade como objeto válido nas distinções de cultura organizacional.

Diante da diversidade de povos que se juntaram na formação do Brasil, dos processos migratórios que se desenvolveram ao longo do tempo (como os italianos, os japoneses, os poloneses, os alemães e outros), dos processos sociais desiguais que se consolidaram, e mesmo os diferentes impactos que a globalização causa em determinadas regiões, alguns autores reconhecem o país como plural, contraditório e multicultural (DIÉGUES JÚNIOR, 1960; DAMATTA, 1985, 1986; FREYRE, 2002; RIBEIRO, 2006; SANTOS e SILVEIRA, 2006). Nesta ordem, as diferenças que marcam o país são bases para distintas categorias de análises, e um destes ângulos é a cultura regional, a partir da qual se procura delimitar particularidades culturais atribuídas a regiões do país.

A multiplicidade regional cultural do Brasil foi inicialmente destacada por autores evolucionistas (HOLANDA, 1995 e FREYRE, 2002). Na visão destes pensadores, esta diversidade estava associada, 
principalmente, a uma questão de raça e de geografia. Esta diversidade foi evidenciada em alguns Modelos (DIÉGUES JÚNIOR, 1960; RIBEIRO, 2006) que procuraram dividir o país em regiões culturais baseados em lógicas aceitas à época.

No entanto, a superação da visão mecânica dos evolucionistas ocorre pelo fato de a dimensão regional, hoje, ser vista como uma questão além da visão exclusivamente geográfica e determinística (SOJA, 1993; GUIBERNAU, 1997; ZAOUAL, 2008). Atualmente, outros olhares se incorporam na análise da perspectiva regional, que não mais fica restrita a um espaço territorial, com fronteiras delimitadas, ou seja, incluem novas vertentes, como os valores, as atitudes, os comportamentos, os fluxos culturais, as simbologias próprias, as ressignificações locais, as dinâmicas comerciais, dentre outros aspectos, que ajudam a distinguir uma região como homogênea em si e heterogênea frente a outras regiões. Esses autores defendem em geral que as delimitações passam a requerer novos elementos de ordem econômica, política, social, cultural e até psicológica, dado que as regiões podem ser entendidas de forma abstrata ou mesmo como representações mentais.

No plano organizacional, o reconhecimento da diversidade cultural e, mais do que isso, de como esta se traduz em interpretações locais e em práticas cotidianas das organizações, abre outras perspectivas de análise que podem superar a visão homogênea ainda presente na literatura sobre o Brasil, tal como defendem Alcadipani e Crubellate (2003, p. 64), ao afirmarem que: "a maioria dos estudos sobre cultura brasileira desenvolvidos no âmbito da administração analisa o tema de forma homogênea, não levando em conta a pluralidade e a heterogeneidade de nosso país e de nossas organizações".

A superação desta posição já começa a ser refletida em trabalhos empíricos recentes que exemplificam a diversidade cultural do país e a sua influência em diferentes organizações:

- Cavedon, Fantinel, Ávila et al. (2008) estudaram os gaúchos que são caracterizados pelos autores como bairristas, e os mineiros, caracterizados como hospitaleiros e desconfiados e que levam estas características para o universo organizacional;

- Rodrigues e Tude (2008) realizaram estudo entre gaúchos e baianos que se entrelaçam através da presença de uma organização gaúcha em território baiano;

- Muzzio e Castro (2008) trabalharam na perspectiva de que o Brasil merece ser analisado, em termos de organizações, a partir de suas distinções culturais regionais, ilustrando suas ideias com uma discussão entre o jeito de ser dos mineiros e dos cearenses;

- Añaña e Nique (2009) exploraram as influências dos valores pessoais e de outros elementos da cultura brasileira na avaliação de uma marca de tênis por meio de quatro subculturas regionais (mineiros, nordestinos, gaúchos e sulistas não gaúchos), e sugeriram a importância dessa informação para a formulação de estratégias de marketing voltadas às diversas regiões do país;

- Strehlau, Claro e Laban Neto (2010) exploraram as diferenças nos valores de consumidores de quatro capitais (Belém, Porto Alegre, Salvador e São Paulo) de diferentes regiões do Brasil, e defendem que tais distinções são importantes para o desencadeamento de estratégias mercadológicas das organizações que atuam no país.

O que estes exemplos mostram é que o Brasil possui uma realidade cultural heterogênea e, sendo assim, merece olhares mais específicos para se conhecerem as suas múltiplas realidades. Os valores, os costumes, as tradições regionais brasileiras influenciam, como se tem mostrado, comportamentos e práticas organizacionais. Neste sentido, as análises organizacionais não deveriam interpretar a cultura brasileira como única, mas sim como dotada de culturas subnacionais que influenciam, no nível intraorganizacional, por exemplo, os comportamentos funcionais e, externamente, por exemplo, as relações com consumidores e outros atores sociais. 


\section{Considerações Finais}

Este estudo teve por finalidade debater a relevância do fator espaço-cultural na configuração da cultura organizacional. Para tanto, foi proposto e debatido um framework que tem por finalidade debater e ilustrar a interação dos elementos globais e regionais, para gerar uma configuração cultural, aqui defendida na esfera regional.

Naturalmente, o modelo não é absoluto em si, até porque elementos contextuais específicos, em especial na esfera setorial, possuem uma sobreposição mais forte entre os elementos globais e regionais. De fato, em geral se observa no mercado a existência de setores que operam com uma lógica global, nos quais seus produtos e serviços são padronizados em nível mundial, situação em que as forças culturais locais tendem a possuir um reduzido papel de interferência, pela própria sobreposição evidenciada. Spicer (2006), por exemplo, cita o setor bancário como uma atividade econômica em que prevalece uma escala global. Porém, organizações que operam com produtos diferenciados e de consumo segmentado, nacional ou regionalmente, como o setor alimentício, de cosméticos ou de entretenimento, tendem a possuir uma maior necessidade de compreender as nuances locais, em virtude da maior interferência dos valores locais na aceitação tácita dos produtos e serviços disponíveis.

No plano organizacional, um exemplo em que o modelo pode ser explorado internamente refere-se à dimensão de administração de recursos humanos. As relações de poder, o nível de comprometimento, o grau de abertura a comportamentos inovadores, dentre outros, podem variar em função de características culturais subnacionais, o que pode levar a ações gerenciais diferenciadas a partir destas ressignificações locais. Outro exemplo possível de explorar, agora voltado para o contexto externo, é na dimensão da administração de marketing. Mecanismos de escolha do consumidor, valoração de pressupostos de consumo, consumo baseado em crenças, dentre outros, são ilustrações de como o componente cultural regional pode levar a uma necessidade de ação gerencial baseada em pressupostos culturais subnacionais (MUZZIO, 2010b). Ainda no plano organizacional, as relações com stakeholders também podem ser influenciadas por elementos culturais subnacionais, tais como valores, crenças, pressupostos ou normas sociais que, reconhecidamente, variam nas diferentes configurações regionais existentes.

A análise das ilustrações apresentadas, na rápida descrição do caso brasileiro, ilustram também uma perspectiva cultural do modelo, mas que também pode ser ampliada para uma dimensão que vai além da natureza do setor sob análise, da especificidade da atividade gerencial considerada, na dimensão de funções. Assim, por exemplo, dentro de uma perspectiva intersubjetiva de análise (CULIFFE, 2010), pode-se compreender que a área financeira de uma organização tende a ser mais homogênea, ao passo que a área de marketing tende a levar em conta as especificidades regionais de forma mais decisiva em seu processo decisorial e gerencial. Caberia, portanto, um aprofundamento desta discussão e a busca de exemplificações de natureza mais específica, por dimensão setorial e por esfera funcional, o que se coloca como desafios para estudos futuros.

Além destes recortes, o modelo se aplica, de forma hipotética, em diferentes tipos de organizações. Utilizando a divisão clássica de organizações empresariais, públicas e sociais, é fácil observar que as configurações de organizações públicas, por exemplo, tanto na visão estrutural quanto operacional e nas diferentes esferas de atuação estatal (federal, estadual e municipal), tendem a ser mais influenciadas pela condição cultural determinada do que pelo espaço regional de sua atuação. $\mathrm{O}$ mesmo poderia ser dito das organizações sociais, em especial pela configuração dos problemas sociais que motivam sua existência. $\mathrm{O}$ que se evidencia, em qualquer dos tipos, é a presença de elementos de contingência regionais que se complementam, pela interação anunciada no modelo, com determinantes de ordem mais ampla. Caberia, por outro lado, compreender estas configurações para casos específicos, o que constitui também um desafio para estudos futuros.

Em geral, mais análises para aprofundar e aperfeiçoar a visão e a lógica do condicionamento cultural e espacial é um desafio para pesquisa em estudos organizacionais. Caberia aos interessados estimular 
pesquisas empíricas que possam evidenciar a natureza das culturas subnacionais. Especificamente no Brasil, análises sobre como se comportam os agentes sociais nas múltiplas realidades regionais, ou ainda como a cultura subnacional se manifesta nos variados setores econômicos ou nas atividades organizacionais. O modelo proposto, oriundo da discussão entre os autores e da pesquisa sistemática de literatura, é na verdade um ponto de partida, que tenta contribuir para um melhor entendimento da dinâmica organizacional, mas que está exposto a aperfeiçoamentos e aprofundamentos.

\section{Referências Bibliográficas}

ALCADIPANI, R.; CRUBELlATE, J. M. Cultura Organizacional Brasileira: generalizações improváveis e conceituações imprecisas. Revista de Administração de Empresas, São Paulo, v. 43, n. 2, p. 64-77, 2003.

AÑAÑA, E. da S.; NIQUE, W. M. O Valor dos Valores: avaliação de uma marca global por meio dos diversos brasis culturais. Revista de Administração Mackenzie, São Paulo, v. 10, n. 3, p. 153-181, 2009.

BAUMAN, Z. Liquid Modernity. Cambridge: Polity Press, 2000.

BERGER, P.; LUCKMANN, T. A Construção Social da Realidade. 24. ed. Petrópolis: Ed. Vozes, 2004.

BLYTON, P. The General and the Particular in Cross-National Comparative Research. Applied Psychology: an international review, v. 50, n. 4, p. 550-595, 2001.

BOISOT, M; MCKELVEY, B. Integrating Modernist and Postmodernist Perspectives on Organizations: a complexity science bridge. Academy of Management Review, v. 35, n. 3, p. 415-433, 2010.

CALÁS, M. B.; ARIAS, M. E. Compreendendo as Organizações Latino-Americanas. In: PRESTES MOTTA, F. C.; CALDAS, M. P. (Org.). Cultura Organizacional e Cultura Brasileira. São Paulo: Atlas, 1997. p. 316-325.

CANCLINI, N. G. Diferentes, Desiguais e Desconectados: mapas da interculturalidade. Rio de Janeiro: Editora UFRJ, 2005.

A Globalização Imaginada. São Paulo: Iluminuras, 2007.

CASTELLS, M. A Sociedade em Rede. São Paulo: Paz e Terra, 1999.

CAVEDON, N. R.; FANTINEL, L. D.; ÁVILA, L. R.; VALADÃO JÚNIOR, V. M. O mate amargo e o doce de leite: entrecruzando as culturas regionais, locais e organizacionais nos Mercados Públicos de Porto Alegre e de Uberlândia. In: ENCONTRO DE ESTUDOS ORGANIZACIONAIS, 05, 2008, Belo Horizonte. Anais eletrônicos... Belo Horizonte: ANPAD, 2008. p. 1-16. 1 CD-ROM.

CHIA, R. Organization Theory as a Postmodern Science In: TSOUKAS, H.; KNUDSEN, C. (Eds.). The Oxford Handbook of Organization Theory: meta-theoretical perspectives. Oxford: The Oxford University Press, 2003. p. 113-140.

COHEN, A. One Nation, Many Cultures: a cross-cultural study of the relationship between personal cultural values and commitment in the workplace to in-role performance and organizational citizenship behavior. Cross-Cultural Research, v. 41, n. 3, p. 273-300, 2007.

CUNLIFFE, A. L. Crafting Qualitative Research: Morgan and Smircich 30 Years On. Organizational Research Methods, p. 01-27, 2010. <http://orm.sagepub.com/content/early/2010/07/23/1094428110373658>. Acesso em: 10 out. 2010.

DAMATTA, R. A Casa e a Rua. São Paulo: Editora Brasiliense, 1985. 
O que Faz o Brasil, Brasil? Rio de Janeiro: Rocco, 1986.

DENZIN, N. K.; LINCOLN, Y. S. (Eds.). The Sage Handbook of Qualitative Research. 3. ed. Thousand Oaks: Sage, 2005.

DIÉGUES JÚNIOR, M. Regiões Culturais do Brasil. Rio de Janeiro: Centro Brasileiro de Pesquisas Educacionais, 1960 .

DONALDSON, L. Organization Theory as a Positive Science In: TSOUKAS, H.; KNUDSEN, C. (Eds.). The Oxford Handbook of Organization Theory: meta-theoretical perspectives. Oxford: The Oxford University Press, 2003. p. 3962.

ELENKOV, D. S.; KIROVA, D. K. Are Cultural Differences in a Small Country Important for International Business? New theory and evidence from Cyprus. Journal of International Business and Economics, v. 8, n. 2, p. 71-78, 2008.

FLICK, U. Uma Introdução à Pesquisa Qualitativa. Porto Alegre: Bookman, 2004.

FREITAS, M. E. Cultura Organizacional: Evolução e Crítica. São Paulo: Thomson Learning, 2007.

FREYRE, G. Casa Grande \& Senzala. 46 ed. Rio de Janeiro: Record, 2002.

GEERTZ, C. A Interpretação das Culturas. Rio de Janeiro: LTC Editora, 1989.

GIDDENS, A. The Consequences of Modernity. Stanford: Stanford University Press, 1990.

Para Além da Esquerda e da Direita. São Paulo: Editora Unesp, 1996.

GOULD, S. J.; GREIN, A. F. Think Glocally, Act Glocally: a culture-centric comment on Leung, Bhagat, Buchan, Erez and Gibson (2005). Journal of International Business Studies, v. 40, n. 2, p.237-254, 2009.

GUIBERNAU, M. Nacionalismos: o estado nacional e o nacionalismo no século XX. Rio de Janeiro: Jorge Zahar Editora, 1997.

HALL, S. A Identidade Cultural na Pós-modernidade. 5. ed. Rio de Janeiro: DP\&A Editora, 2001.

HARVEY, D. Condição Pós-Moderna: uma pesquisa sobre as origens da mudança cultural. São Paulo: Edições Loyola, 1992.

HATCH, M. J.; YANOW, D. Organization Theory as an Interpretative Science In: TSOUKAS, H.; KNUDSEN, C. (Eds.). The Oxford Handbook of Organization Theory: meta-theoretical perspectives. Oxford: The Oxford University Press, 2003. p. 63-87.

HOFSTEDE, G. Cultures Consequences: international differences in work-related values. Beverly Hills: Sage, 1980.

HOLANDA, S. B. de. Raízes do Brasil. 26. ed. São Paulo: Companhia das Letras, 1995.

KOSTOVA, T; ROTH, K. Adoption of an Organizational Practice by Subsidiaries of Multinational Corporations: institutional and relational effects. Academy of Management Journal, v. 45, n. 1, p. 215-233, 2002.

KUMAR, K. Da Sociedade Pós-Industrial à Pós-Moderna: novas teorias sobre o mundo contemporâneo. Rio de Janeiro: Jorge Zahar Editora, 1997.

LAROCHE, M.; PAPADOPOULOS, N.; HESLOP, L.; BERGERON, J. Effects of subcultural differences on country and product evaluations. Journal of Consumer Behaviour, v. 2, n. 3, p.232-247, 2003.

LEFEBVRE, H. The Production of Space. Malden, MA: Blackwell Publishing, 1991. 
LENARTOWICZ, T.; ROTH K. Does Subculture within a Country Matter? A cross-cultural study of motivational domains and business performance in Brazil. Journal of International Business Studies, v. 32, n. 2, Second Quarter, p. 305-325, 2001.

LIPOVETSKY, G. Tempo Contra Tempo, ou a Sociedade Hipermoderna In: LIPOVETSKY, G.; CHARLES, S. Os Tempos Hipermodernos. São Paulo: Editora Barcarolla, 2004. p. 49-103.

LLOYD, C. Thinking about the Local and the Global in the Algerian Context. Oxford Development Studies, v. 30 , n. 2, p.151-163, 2002.

MACNAB, B.; WORTHLEY, R.; JENNER, S. Regional Cultural Differences and Ethical Perspectives within the United States: avoiding Pseudo-emic Ethics Research. Business and Society Review, v. 115, n. 1, p. 27-55, 2009.

MARTIN, J. Culture in Organizations: three perspectives. New York: Oxford University Press, 1992.

Meta-Theoretical Controversies in Studying Organizational Culture In: TSOUKAS, H.; KNUDSEN, C. (Eds.) The Oxford Handbook of Organization Theory: meta-theoretical perspectives. Oxford: The Oxford University Press, 2003.

.; FROST, P. The Organizational Culture War Games: a struggle for intellectual dominance. In: CLEGG, C. H.; NORD, W. (eds.), Handbook of Organizations Studies. London: Sage, 1996.

MCSWEENEY, B. Dynamic Diversity: variety and variation within countries. Organization Studies, v. 30, n. 9, p. 933-957, 2009.

MEEK, V. L. Organizational Culture: origins and weaknesses. Organization Studies, v. 9, n. 4, p. 453-473, 1988.

MITCHELL, K. Cultural Geographies of Transnationality. Handbook of Cultural Geography. 2002. SAGE Publications. Disponível em: <http://www.sage-ereference.com/hdbk_culturegeo/Article_n4.html>. Acesso em: 19 out. 2010.

MORGAN, P. I.; OBBONNA, E. Subcultural Dynamics in Transformation: a multi-perspective study of healthcare professionals. Human Relations, v. 61, n. 1, p. 39-65, 2008.

MUZZIO, H.; Cultura Organizacional e Perspectivas Estratégicas da Regionalidade Cultural Brasileira In: ENCONTRO DE ESTUDOS ORGANIZACIONAIS, 06, 2010, Florianópolis. Anais eletrônicos... Florianópolis: ANPAD, 2010a. p. 1-16. 1 CD-ROM.

Cultura Organizacional na Perspectiva Cultural Regional Brasileira. Revista Brasileira de Gestão de Negócios, São Paulo, v. 12, n. 37, p. 447-463, 2010b.

; CASTRO, D. J. de. Quantos Somos Nós? Uma Reflexão sobre os Brasis Culturais. In: ENCONTRO DE ESTUDOS ORGANIZACIONAIS, 05., 2008, Belo Horizonte. Anais eletrônicos... Belo Horizonte: ANPAD, 2008. p. 1-16. 1 CD-ROM.

NELSON, R. E.; GOPALAN, S. Do Organizational Cultures Replicate National Cultures? isomorphism, rejection and reciprocal opposition in the corporate values of three countries. Organization Studies, v. 24, n. 7, p. 1115-1151, 2003.

PAASI, A. Boundaries in a Globalizing World. Handbook of Cultural Geography. 2002. SAGE Publications. Disponível em: <http://www.sage-ereference.com/hdbk_culturegeo/Article_n25.html>. Acesso em: 15 out. 2010.

PESQUEUX, Y. Culturas, Culturalismo e Globalização. In: CHALAT, J-F.; FACHIN, R.; FISCHER, T. (Org.). Análise das Organizações, v. 2: poder, cultura, subjetividade e vida simbólica. Porto Alegre: Editora da UFRGS, 2007. p. 281-306.

PETERSON, M F; SMITH, P. B. Does National Culture or Ambient Temperature Explain Cross-National Differences in Role Stress? No Sweat! Academy of Management Journal, v. 40, n. 4, p. 930-946, 1997. 
PETTIGREW, A. M. On Studying Organizational Cultures. Administrative Science Quarterly, v. 24, n. 4, p. 570-581, 1979.

PRASAD, A.; PRASAD, P., Mix, Flux and Flows: the globalization of culture and its implications for management and organizations. The Journal of Global Business Issues, v. 1, n. 2, p. 11-20, 2007.

RIBEIRO, D. O Povo Brasileiro: a formação e o sentido do Brasil. São Paulo: Companhia de Bolso, 2006.

RODRIGUES G. K. M.; TUDE, J. M. Culturas Regionais no Brasil: um estudo sobre as percepções mútuas de gaúchos e baianos no ambiente de trabalho. In: ENCONTRO DE ESTUDOS ORGANIZACIONAIS, 05, 2008, Belo Horizonte. Anais eletrônicos... Belo Horizonte: ANPAD, 2008. p. 1-16. 1 CD-ROM.

SANTOS, M.; SILVEIRA, M. L. O Brasil: território e sociedade no início do Século XXI. Rio de Janeiro: Editora Record, 2006.

SARWONO, S. S.; ARMSTRONG, R.W. Microcultural Differences and Perceived Ethical Problems: an international business perspective. Journal of Business Ethics, v. 30, n. 1, p. 41-56, 2001.

SCHEIN, E. H. Organizational Culture and Leadership. 3a. ed. San Francisco: Jossey-Bass, 2004.

SCOTT, W. R. Institutions and organizations. 2. ed. Sage Publications, 2001.

SINGH, S. K.; SRINIVASAN, V.; SISTA, S.; PARASHAR, M. Cross Cultural Conceptualisations: a case for multiple national cultures in India. Indian Institute of Management Bangalore Management Review, v. 20, n. 3, p. 249-262, 2008 .

SMIRCICH, L. Concepts of Culture and Organizational Analysis. Administrative Science Quarterly, v. 28, n. 3, p. 339-358, 1983.

SOIN, K.; SCHEYTT, T. Making the Case for Narrative Methods in Crosss Cultural Organizational Research. Organizational Research Methods, v. 9, n. 1, p. 55-77, 2006.

SOJA, E. W. Geografias Pós-Modernas: a reafirmação do espaço na teoria social crítica. Rio de Janeiro: Jorge Zarah Editor, 1993.

SPICER, A. Beyond the Convergence-Divergence Debate: the role of spatial scales in transforming organizational logic. Organization Studies, v. 27, n. 10, p. 1467-1483, 2006.

STREHLAU, V. I.; CLARO D. P.; LABAN NETO, S. A. Em Busca da Identificação de Valores Regionais: subsídios para discussão de estratégias mercadológicas. Revista de Administração da USP, São Paulo, v.45, n.2, p.116-129, 2010.

TOMITÃ, V.; STUPARU, D.; TANCIU, M.; DANIASA, C. The Effect of Organizational Culture on Quality Management Practices. Economics, Management, and Financial Markets, v. 5, n.2, p. 304-309, 2010.

TRICE, H. M.; BEYER, J. M. Studying Organizational Cultures through Rites and Ceremonials. Academy of Management Review, v. 9, n. 4, p. 653-669, 1984.

TSUI, A. S.; NIFADKAR, S. S.; OU, A. Y. Cross-National, Cross-Cultural Organizational Behavior Research: advances, gaps, and recommendations. Journal of Management, v. 33, n. 3, p. 426-478, 2007.

TURNER, B. A. Sociological Aspects of Organizational Symbolism. Organization Studies, v. 7, n. 2, p.101-115, 1986.

VAN DEN BERG, P. T.; WILDEROM, C. P.M. Defining, Measuring, and Comparing Organisational Cultures. Applied Psychology: An International Review, v. 53, n. 4, p. 570-582, 2004. 
VÄYRYNEN, R. Regionalism: old and new. International Studies Review, v. 5, n. 1, p. 25-51, 2003.

WILLMOTT, H. Organization Theory as a Critical Science? In: TSOUKAS, H.; KNUDSEN, C. (Eds.). The Oxford Handbook of Organization Theory: meta-theoretical perspectives. Oxford: The Oxford University Press, 2003. p. 88112.

ZAOUAL, H. Globalização e Diversidade Cultural. 2. ed. São Paulo: Cortez, 2008. 